\title{
Big Data, Extracting Insights, Comprehension, and Analytics in Cardiology: An Overview
}

\author{
Hui Xiao $\mathbb{D}^{1},{ }^{1}$ Sikandar Ali $\left(\mathbb{D},{ }^{2}\right.$ Zhen Zhang, ${ }^{1}$ Muhammad Shahzad Sarfraz, ${ }^{3}$ Fang Zhang, \\ and Mohammad Faisal (iD ${ }^{4}$ \\ ${ }^{1}$ Zhongnan Hospital of Wuhan University, Information Center, Wuhan 430071, China \\ ${ }^{2}$ Department of Computer Science and Technology, China University of Petroleum-Beijing, Beijing 102249, China \\ ${ }^{3}$ Department of Computer Science, National University of Computer and Emerging Sciences Islamabad, \\ Chiniot-Faisalabad Campus, Chiniot, Pakistan \\ ${ }^{4}$ Department of Computer Science and Information Technology, University of Malakand, Chakdara, Pakistan
}

Correspondence should be addressed to Hui Xiao; znhospitalxh@163.com and Sikandar Ali; sikandar@cup.edu.cn

Received 8 December 2020; Revised 9 January 2021; Accepted 20 January 2021; Published 31 January 2021

Academic Editor: Iván García-Magariño

Copyright (C) 2021 Hui Xiao et al. This is an open access article distributed under the Creative Commons Attribution License, which permits unrestricted use, distribution, and reproduction in any medium, provided the original work is properly cited.

\begin{abstract}
Healthcare system facilitates the treatment of patients with the support of wearable, smart, and handheld devices, as well as many other devices. These devices are producing a huge bulk of data that need to be moulded for extracting meaningful insights from them for the useful use of researchers and practitioners. Various approaches, methods, and tools are in use for doing so and to extract meaningful information in the field of healthcare. This information is being used as evidence to further analyze the data for the early care of patient and to devise treatment. Early care and treatment can facilitate healthcare and the treatment of the patient and can have immense potentiality of dropping the care cost and quality refining of care and can decrease waste and chances of error. To facilitate healthcare in general and cardiology in specific, the proposed study presents an overview of the available literature associated with big data, its insights, and analytics. The presented report will help practitioners and researchers to devise new solutions for early care in healthcare and in cardiology.
\end{abstract}

\section{Introduction}

The increase in use of smart devices such as sensor, actuator, and wearable devices, as well as other devices, has produced massive amount of data that need to be shaped in a structure way to mine the information and useful insights for the useful use of research and practice. This increase of information can yield research issues and challenges as extracting useful information becomes a challenging task for research. The useful insights once drawn in a successful way can ultimately care the patient and provide effective treatment in the early stage. Diverse approaches, methods, and mechanisms are in practice to tackle the issues of big data and its analytics in the field of healthcare in general and cardiology in specific.

The role of data processing and information in healthcare has always been vital in healthcare for decision-making and its provision. Medical big data is produced from the communication and digitization in healthcare. Healthcare providers and hospital industry provide a huge amount of data from other segments, such as medical equipment, medical insurance medical research, and life science. Huge amount of data exists, which grasps the potential of support of healthcare and medical tasks. The integration of machine learning, artificial intelligence, and advanced analytics offers numerous opportunities for transmuting such data into actionable and expressive insights for supporting decisionmaking. This can ultimately make availability of patient care at high quality and real-time situation response and can protect lives on the clinical side and develop the services and processes, improve the use of resources, and minimize the costs on the maintenance and financial front $[1,2]$.

With the rise of advanced approaches such as analytical techniques and approaches, the stakeholders of healthcare 
can not only connect the data power for historical analysis of data but also predict future outcomes with predictive analytics for defining best accomplishment for present situation $[3,4]$. Conventionally, the practitioners of clinic rely on reserved information accessible to them and their past involvement for treatment of patients. Data availability from diverse sources deals with the chance to have a complete thought of patient well-being. The use of cutting-edge technologies against such data aids access to the appropriate information at precise place and accurate time for delivering precise care [5].

The proposed study presents an overview of the available literature associated with big data, its insights, and analytics. The process of search for the proposed study was done in the popular libraries with the aim of obtaining associated materials. The presented report will help practitioners and researchers to devise new solutions for early care in healthcare and in cardiology.

The remainder of the paper is organized as follows: Section 2 presents the interrelated research to current study. Section 3 presents library-based search process for the proposed study. Section 4 concludes the paper.

\section{Related Work}

Several approaches have been in practice to tackle diverse issues of big data and its analytics in healthcare. Pevnick et al. [6] offered a review that discusses the current and upcoming devices intended for measuring the actions of heart rhythm, heart rate, and thoracic fluid. Various frameworks were presented, which classify and understand the wearable devices. Mehta et al. [7] presented a systematic mapping study for analyzing and identifying the research studies on analytics of big data and use of artificial intelligence in healthcare. The study identified 2421 papers for the year's ranges from 2013 to February 2019. These papers were evaluated, and the results show that the study will support the necessity in the use of technologies in healthcare. Atitallah et al. [8] surveyed the literature associated with the DL and IoT applications for smart cities' developments. Initially, the basics of IoT were defined followed by the characteristics of IoT-produced big data. After that, the various structures used for analytics of IoT big data were presented. The common DL models were surveyed and reviewed the current research employing the IoT and DL for developing services and smart applications for smart cities. The existing issues and challenges encountered throughout the smart city's development were outlined. Kazmierska [9] presented a study on the needs of community in translating multisource data into clinical decision aids.

Ben-Assuli et al. [10] demonstrated power prediction of four popular algorithms and matched their accuracy in congestive heart failure predicting initial patient mortality. The results show that the current models outperform those described in the literature. The results further support the policy-makers in allocation of resources for establishment of comprehensive systems of integrated health IT aiming at simplification of analytics of ML. Dipti Itchhaporia [11] analyzed the existing application and state of machine learning approaches and artificial intelligence in cardiovascular medicine. The effects of emerging technologies on cardiovascular medicine are emphasized for providing understanding to the clinical practice and to find probable patient assistances. Nazir et al. [12] provided a wide-ranging overview of the available big data studies in cardiology. The study followed a protocol of systematic literature review for presenting the published material from 2008 till 2018 associated with big data features, applications, and analytics in cardiology field. The authors identified 190 potential studies and analyzed them. These studies were published in conferences, books, journals, and many other online materials. The study was presented as an evidence for the researchers and practitioners to devise novel solutions in the area of interest. Nazir et al. [13] presented a comprehensive review of the 10 years from 2008 to 2018 associated with the visualization of big data in the area of cardiology. The study identified 53 prospective papers related to visualization of big data in cardiology. The study was based on protocol with defined research questions, inclusion and exclusion criteria, and quality criteria. These identified studies were analyzed according to the defined research questions. The study highlighted the increase of the number of researches in the area and focused on further research and innovations in the field. These studies were done in order to support the usage of big data in healthcare.

Bizopoulos and Koutsouris [14] surveyed applications of deep learning that uses structured data and signal and imaging modalities from cardiology. The benefits and limitations of applications of deep learning in cardiology and in medicine in general are discussed. Cannière [15] examined the developments of heart rate variability factors during short-term interval all the way through cardiac rehabilitation. Electrocardiography signals, documented with the help of wearable device in 129 patients following cardiac rehabilitation program, were analyzed. The findings of the study present appreciated insights into disease monitoring during cardiac rehabilitation in future application.

\section{Library-Based Search Process}

This study offers to present an overview of the existing approaches and methods for big data, its analytics, and insights in cardiology. Various popular libraries such as ScienceDirect, IEEE, Springer, and Wiley were searched with the aim of obtaining associated materials interconnected to the current study. The information gathered from these libraries was analyzed and presented from different perspectives in the form of different tables and figures. This information includes the type of article, number of publications, topics covered, subject areas, and publication titles. Initially, the library of ScienceDirect was checked and the following information was obtained. Figure 1 depicts the types of articles with publications. The figure shows that a bigger number of publications were in the form of research article.

Figure 2 presents the articles in total with the given year. More publications are shown in the year 2020, which shows the increase in number of researches. 


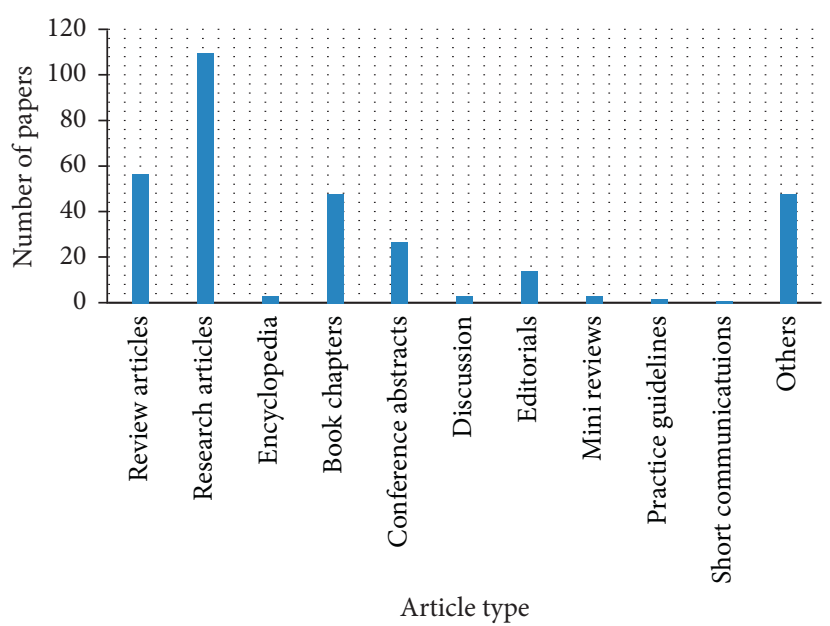

Figure 1: Article types.

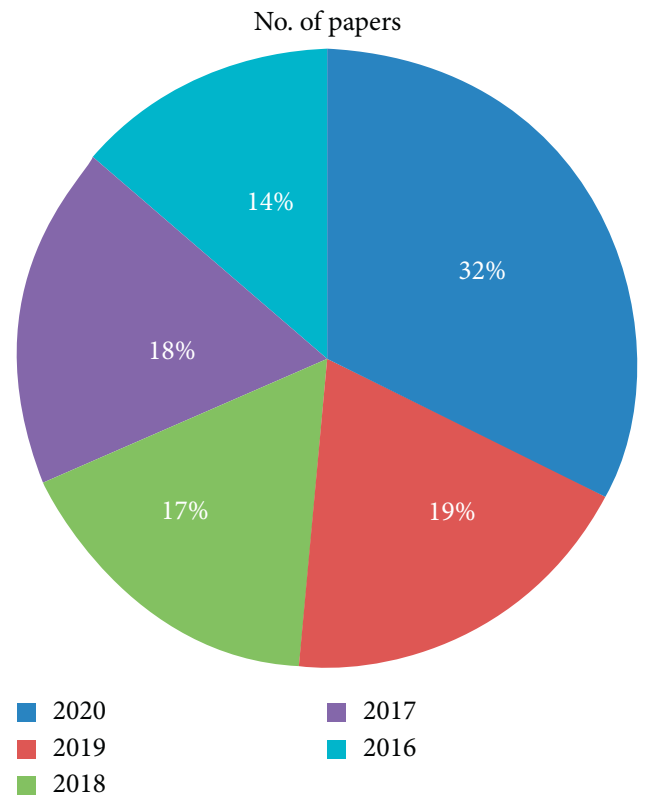

Figure 2: Number of papers published.

Figure 3 depicts the subject areas with the number of publications.

The library of IEEE was searched for the purpose of identifying relevant information. Figure 4 represents the information of publication topics with the total number of articles published.

The paper type and total number of publications in the same library are shown in Figure 5.

Figure 6 presents the conference location with the number of publications.

After this, the library of Springer was searched to view the information for the purpose of analysis. Figure 7 depicts the type of articles with the number of publications.
The discipline with the total number of articles is shown in Figure 8. The purpose of this search was to identify the disciplines covered by the area.

The libraries of Wiley and Taylor \& Francis were also part of the proposed study. These libraries were searched for relevant information and analysis. Figure 9 depicts the publication types with total number of articles published. In the figure, it is shown that more papers are published with type journal.

Figure 10 presents the number of publications in the given years from 2016 till 2020.

After the statistics were obtained, the papers were reviewed and the details with short descriptions of the papers were given. Table 1 shows the big data and its analytics in cardiology. 


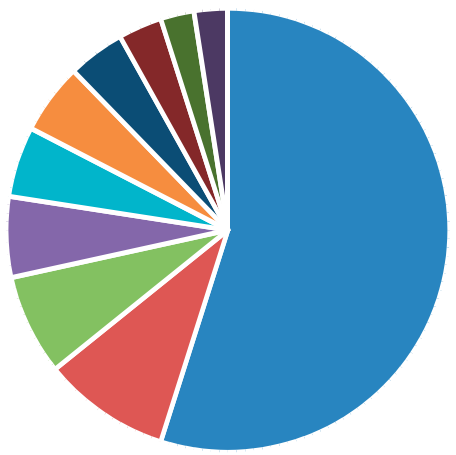

- Medicine and dentistry

- Biochemistry, genetics, and molecular biology

- Computer science

- Nursing and health professions

- Pharmacology, toxicology, and pharmaceutical science

- Social sciences

- Engineering

- Business, management, and accounting

- Chemical engineering

- Decision sciences

FIgURE 3: Subject area with number of articles.

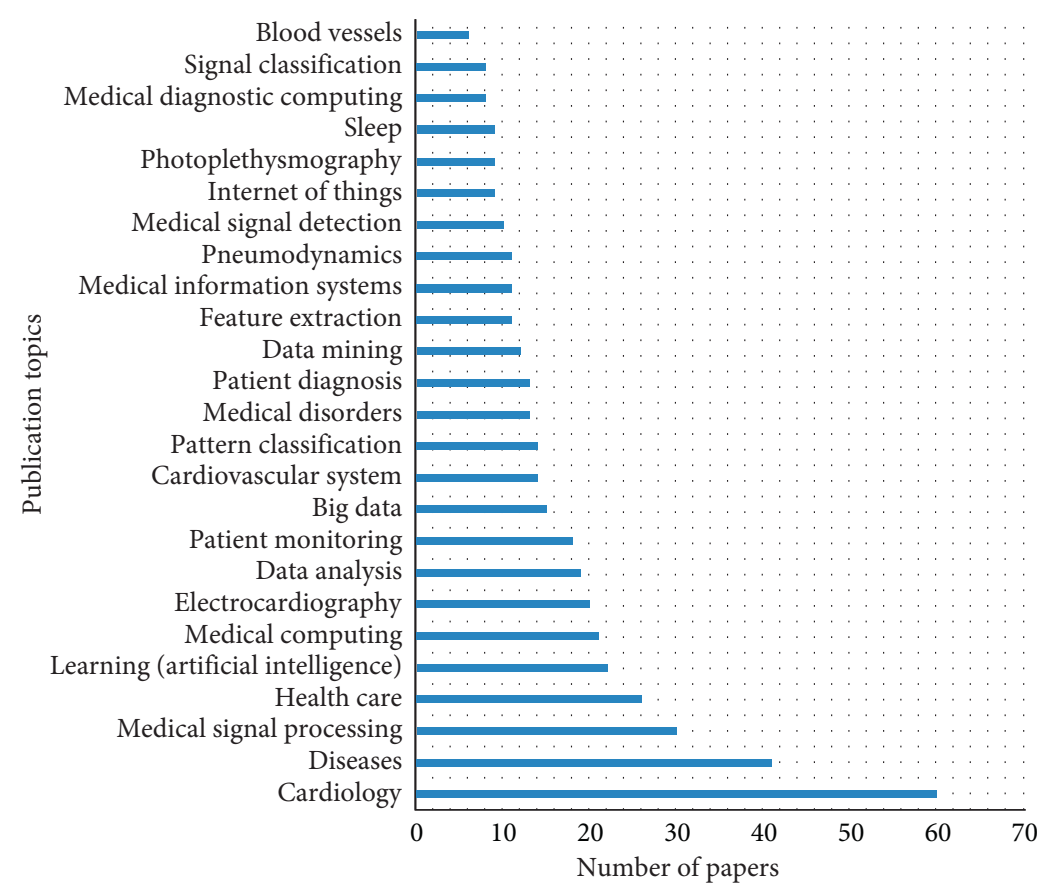

Figure 4: Publication topic with number of articles. 


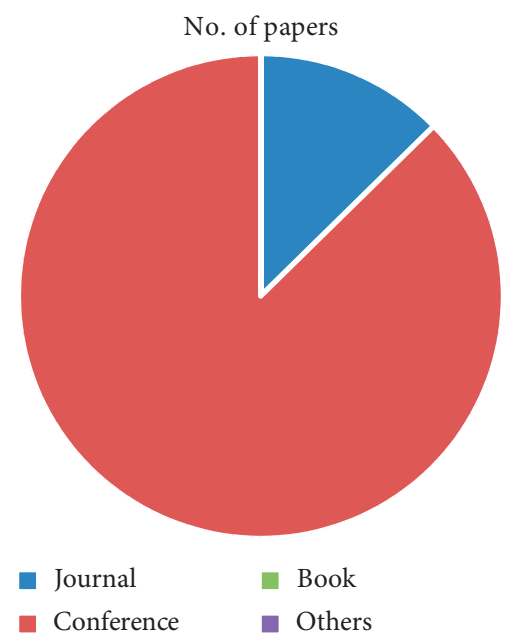

Figure 5: Paper type with number.

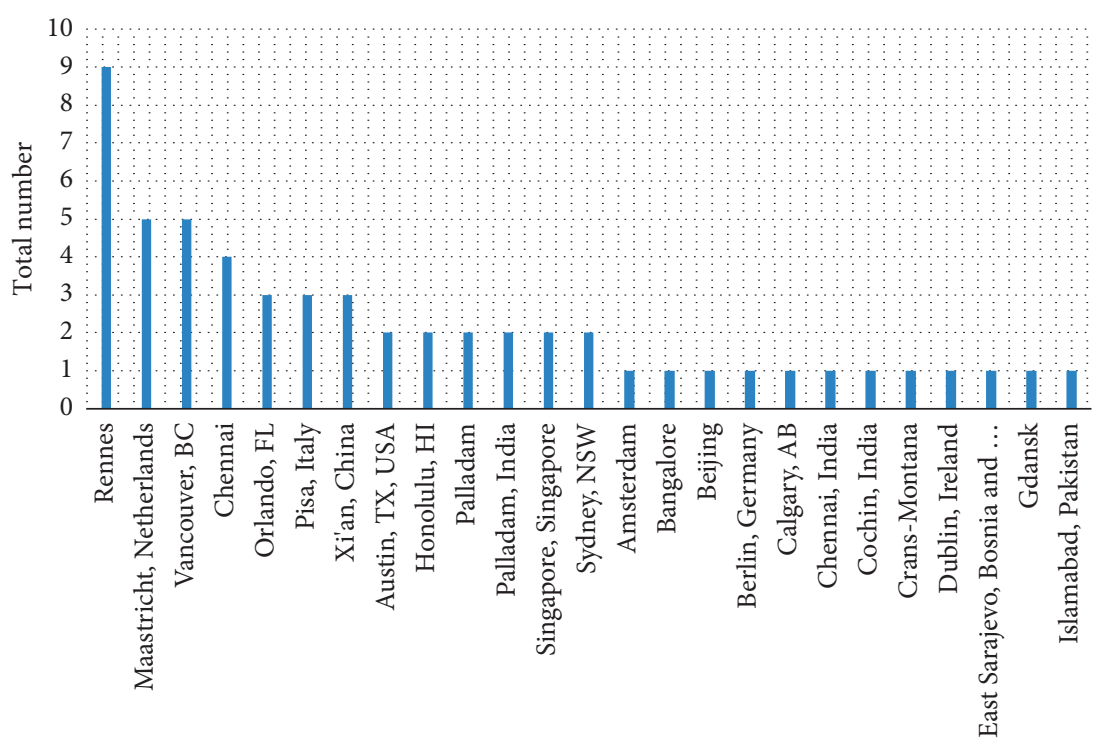

Conference location

FIGURE 6: Conference location with number of articles.

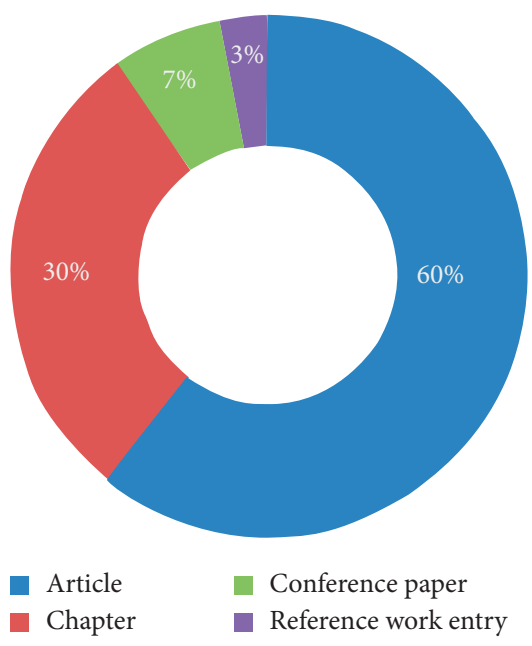

Figure 7: Content type. 


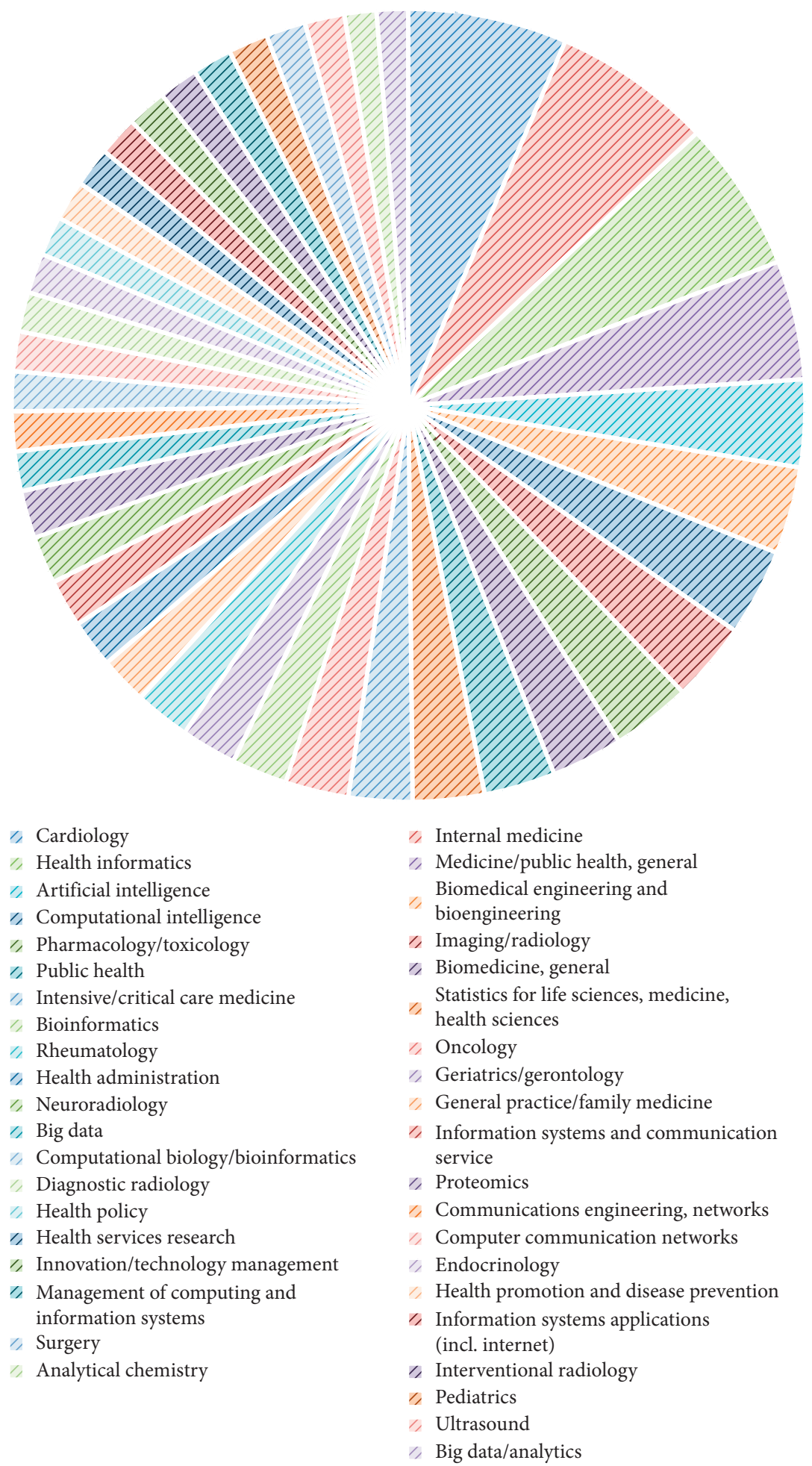

Figure 8: Discipline with number of articles. 


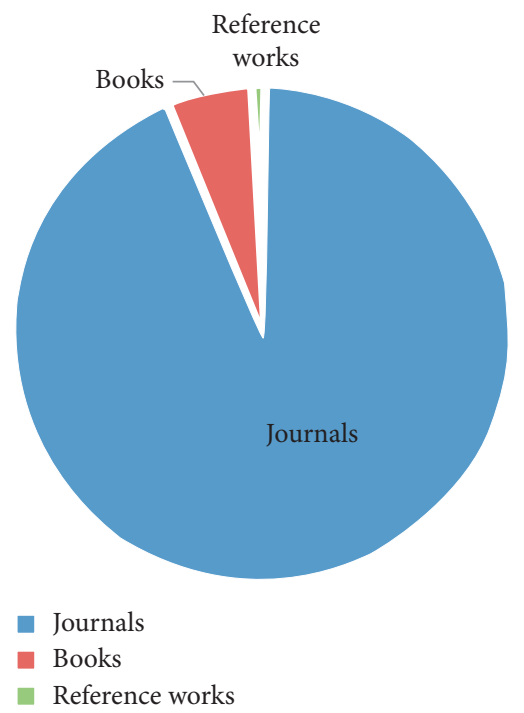

Figure 9: Publication type with number of papers.

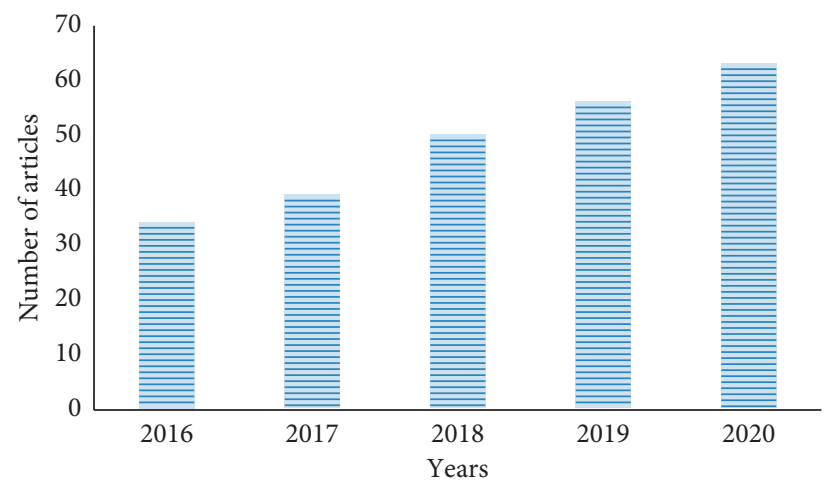

Figure 10: Publication in the year.

TABLe 1: Work in the area of big data and its analytics in cardiology.

Method

Description

[6] Wearable technology for cardiology

Devices of wearable technology were intended for measuring the heart rhythm, heart rate, activity, and thoracic fluid. For classification and understanding, a framework was given to the wearable devices for improving healthcare.

475 papers from PubMed library were examined for solutions of telemedicine to improve medication adherence of

[16] Technology for cardiovascular disease patient cardiovascular disease patient. 74 articles were assessed. The articles exhibited that suggestions associated with solutions of telemedicine are typically conflictive. The use of SMS was considered for patients regarding their medication because of forgetfulness.

A system of health proactive monitoring is planned for cardiac patients. In the study, an electronic band is worn by the patient and the real-time situation of health and system of e-health are

Big data for monitoring of proactive healthcare of patients of chronic diseases

the patient to take proactive process beside some of the abnormal states in their health and further supports the doctors to monitor the health of patient on a regular basis. 
TABLE 1: Continued.

\begin{tabular}{|c|c|c|}
\hline Citation & Method & Description \\
\hline$[18]$ & $\begin{array}{l}\text { Deep learning network in left ventricular volumes } \\
\text { identification in cardiac MRI }\end{array}$ & $\begin{array}{l}\text { The research has established left ventricular volumes approach } \\
\text { of identification without segmentation by deep learning } \\
\text { technology and the data set form large-scale cardiac MRI from } \\
\text { second annual data science bowl in } 2016\end{array}$ \\
\hline$[19]$ & Medical data mining and heart disease & $\begin{array}{l}\text { The study offered review of the associated techniques of data } \\
\text { mining for finding of diseases classes and heart failure. } \\
\text { Additionally, emphasis is given on sequential mining. }\end{array}$ \\
\hline$[20]$ & ML horizon in cardiac hybrid imaging & $\begin{array}{l}\text { The study presented summary of the fundamental notions in } \\
\text { ML and its applications in standard cardiac imaging }\end{array}$ \\
\hline$[21]$ & Mobile heart rate monitoring system for patient of MI & $\begin{array}{l}\text { Application of mobile for the patient of myocardial infarction } \\
\text { (MI) is presented to preserve heart rate tracking and with stress- } \\
\text { free pursuing for emergency support }\end{array}$ \\
\hline$[22]$ & Clinical guidelines in cardiology run-through in Sudan & $\begin{array}{l}\text { Interviews in the two main cardiac hospitals of Sudan were led } \\
\text { and an exploratory study among the hospitals' doctors was } \\
\text { prepared for examining the perceptions of a huge population of } \\
\text { prescribers of the subject examined }\end{array}$ \\
\hline [23] & Big health data & $\begin{array}{l}\text { Management of cardiac data and operative concept of } \\
\text { remodelling to examine early symptoms of heart failure is } \\
\text { presented }\end{array}$ \\
\hline
\end{tabular}

[24] Big health data records for early and late translational cardiovascular research

[25] Factorization of tensor for precision medicine in failure of heart with preserved ejection fraction

[26]

Mobile messaging applications' effect on knowledge of cardiac patients with risk of coronary artery disease and healthy lifestyle adherence

[27] SVM for classification of biomedical signal on IoT platform Heart failure prevention

The research censoriously reviewed the challenges of big data before time and after the event stages of research in translational cardiovascular disease

The study examined the related woks on factorization of tensor applications in the associated biomedical field of phenotyping and genotyping

The research led a study from January to April 2017 in Klang Valley's teaching hospital for determining the effect of mobile messaging applications on patients with coronary artery disease and observation of healthy life

The study observed the signal over digital signal processor and then computed the blood oxygen saturation, heart rate, and

blood pressure. SVM was considered for the purpose of showing the data and its classification into unhealthy, healthy, and very unhealthy and designates accuracy of classification prediction. Risk factors of heart failure and focus on prevention are specified

[29] Statistical shape models of the heart

The study presented summary of the collected works of statistical shape models in cardiac imaging

[30] Classifying mining techniques for the accessible clarification Framework to use healthcare data for attributes based heart [30] for heart disease prediction disease prediction is presented in the study

[31] Statistical based recommendation model for the patients of Smart system of recommendation is presented for patients with heart disease heart disease in the fields of medical informatics and e-health

[32] Modelling 4D for rapid assessment of biventricular function in The study has quantified 4D biventricular function from congenital heart disease

[33] Big database applications and forthcomings in cardiology

[34] Approach of big data to myocyte membrane analysis

The study presented an approach for identification of particular pathological ion dynamics responsible for abnormal electrical behaviour practiced through the experiment

The research inspected the patterns where the patients of heart attack are transferred between the hospitals. The three key factors in transferring destinations are:

Distance, quality, or relationship? Interhospital transfer of patients with heart attack

(i) The distance between sending and receiving in hospitals

(ii) Widely reported quality measures of receiving hospitals as specified by whether they are related with the same multihospital system

(iii) The relationship between sending and receiving hospitals 
TABLE 1: Continued.

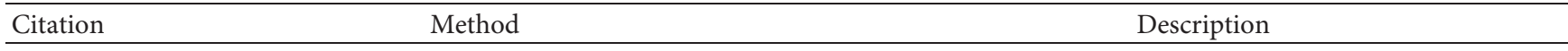

[36] Feature analysis and coronary artery heart disease data sets

37] Mapping of ventricular tachycardia in patients with heart structural disease

Patients' baseline characteristics with heart failure and

[38] preserved ejection fraction during admission with acute heart failure in Saudi Arabia

[39] Cardiovascular dysautonomias diagnosis and treatments through data mining

[40] Approach of data transmission based on adaptive energy efficiency for prediction of heart disease

Analytics of big data in prediction of heart attack

[42] Cloud computing for myocardial fibre information in vivo

[43] Using big data for assessing the risks of arrhythmia

ML framework and imaging based big data for rapid phenotyping of left ventricular diastolic function

Insights from echo reports of paediatric disease of heart

[46]

Framework of probabilistic data driven for scoring the preoperatives recipient-donor heart transplant survival

[47]

Identification of heart arrhythmia through big data-based extraction of fuzzy partition rules

[48]
Integrate the experimental results of the examination of ML which are applied on varied data sets aiming at the coronary artery heart disease

The paper has focused on the procedure of mapping ventricular tachycardia; the conventional and novel technique of mapping and the details of some methodological tips are given

Saudi Arabian patients with HFpEF were examined with acute heart failure. The clinical characteristics, signs, and indications of heart failure, echocardiographic findings, and medications during admission and at hospital discharge were determined.

The authors established a cardiovascular dysautonomias identification system for the prediction of appropriate

treatments and diagnosis for patients with cardiovascular dysautonomias through the data set extracted from the ANS unit of University Hospital Avicenne in Morocco

The research developed an adaptive energy resourceful transmission system which can recognise the important events like myocardial infarction and reduce data transmission from the devices

The study identified the analytics uses in big data for the prevention and prediction of heart attack, privacy of the patients, and the challenges for the use of technology in big data. The study analyzed the national and international databases for the proposed study.

System of cloud-based investigation is intended for cardiac images and link services of computation for remote sharing. A method for postprocessing of image is defined as important service for obtaining information on in vivo myocardial fibres. The research presented an algorithm to involuntarily identify the $\mathrm{R}, \mathrm{S}$, and $\mathrm{T}$ wave peaks in epicardial electrogram signals The study proposed that the cardiac biomechanics produce adequate information which can affect ML and framework of big data analytics for function of automated left ventricular diastolic assessment

The entity site-feature values are mined in triples in the report of echo and then on the ground of this prediction of the level of risk

The technique of Bayesian belief networks is used. The approach contains four phases; the first and second phases of the data are preprocessed and a set of predictors are produced based on different variable selection method. The medically associated variables are added to the list of variables in the third phase, and in the last phase the Bayesian belief networks technique is applied.

The research presented a novel semiautomatically fuzzy partition rules for facilitating an accurate and robust aspect into cardiac arrhythmia. The approach of text mining is demonstrated and applied to large data set containing freely existing articles in the PubMed library. The information is mined and then put to the experimental data and expert information for facilitating robust system to tackle the issues arising through the assessment of medical big data.

The research has established a central monitoring system for patients of large set of health records as input. It is intended to mine the essential information from large set of medical records through the method of map reduction. By using this approach, it can be decided whether there is patient normality or abnormality. 
TABLE 1: Continued.

\begin{tabular}{lcc}
\hline Citation & Method & Description \\
\hline [49] & $\begin{array}{c}\text { Cardiovascular risk clustering factors highlighted the coronary } \\
\text { artery calcium as a strong clinical discriminator }\end{array}$ & $\begin{array}{c}\text { The authors studied the relations between cardiovascular risk } \\
\text { clustering and the discriminators of disease of cardiovascular } \\
\text { factors }\end{array}$ \\
\hline
\end{tabular}

The current technological and clinical improvements containing wearable health tracking devices, smartphone

[50] Mobile health initiatives for cardiovascular disease devices, and social media for supporting behaviour factors of risk for cardiovascular disease in terms of smoking, physical inactivity, and suboptimal nutrition

[51] Sudden cardiac death with risk stratification and computational cardiology

[52] Technology of smartphone in cardiology

Visualization of cardiovascular MRI challenges and opportunities

Big data in cardiology

Cardiovascular medicine big data, health informatics, and future

[56]

Tool for the MIMIC-II database, a web-based data visualization

[57] Connecting the dots: from big data to healthy heart

[58] Libraries implementation of open-source data visualization of web portal for patients of diabetes

[52] Technology of smartphone in cardiology

Machine learning approaches in detection of ischemic heart

[59] Machine learning approaches in
disease

[60] Paediatric cardiovascular disease in the era of transparency in healthcare using big data

[61] Data visualization: science on the map

[62]

Harnessing the heart of big data

[63]

4D OCT in developmental cardiology
The study defined guidelines of what is to be required for making the translational step, through the comparatively well intended cases required or drug induced long QT as a case of syndrome

The research presented various applications of smartphone based technologies in cardiology and gave a review of them

The study offered an overview of the existing associated works of visualization approaches and emphasis on the visualizing imagery issues resulting from $2 \mathrm{D}$ myocardial tagging in CMR

The article's purpose is the three encouraging big data applications in cardiovascular care, with "proof-of-concept" challenges to be met if the encouraging data is to be comprehended

The study offered a report on cardiovascular medicine big data, health informatics, and future

The objectives of the study are:

(a) to build an interactive and

(b) data visualization tool based on web MIMIC-II

Furthermore, the research mainly offered two features of exploration and comparison. The first feature helps the patient cohort within MIMIC-II and visualized the distribution of

various variables including administrative, clinical, and demographic variables within the selected cohort. The second feature helps the users in selection of two patient cohorts and visual comparison with other variables.

The study designated various sources of big data in cardiology followed by talk over the possibilities of building the best use of data-driven knowledge production models

A web portal is employed for improved communications of diabetes patients with doctors for the process of identification and handling of diabetes. Medical data are offered on the portal based on open-source libraries.

The research discusses the details of diverse applications of technologies of smartphone in cardiology

SVM and Osuna were used for detecting the ischemic disease of heart. The principal component analysis algorithm was also used.

The research offered a review on analytics of big data impact in paediatric cardiovascular disease and its possible issues of transparency in distribution of care A tool box for data visualization

The paper discussed the following:

(i) Report on big data science research

(ii) Potential of data science to support examinations of cardiovascular diseases

(iii) Challenges and opportunities

The chapter emphasizes on numerous existing solutions and gives review of the perspective in the evaluation of $4 \mathrm{D}$ OCT imaging for cardiovascular system in the past several years 
TABLE 1: Continued.

\begin{tabular}{lcc}
\hline Citation & Method & Description \\
\hline [64] & $\begin{array}{c}\text { Kinect-based gesture prediction in volumetric visualization of } \\
\text { heart from CMR imaging }\end{array}$ & $\begin{array}{c}\text { The research aims to offer a virtual human heart from medical } \\
\text { imaging data with incorporation of collaborating interface using } \\
\text { visual 3D holographic, haptic, and sonic feedback }\end{array}$ \\
\hline
\end{tabular}

[65] Feast for the eyes

The research presented the existing data visualization uses and reviewed the probable issues, benefits, and applications of libraries

[66] Cardiac 4D ultrasound imaging

Overview of the technological developments for volumetric imaging of the heart beat with the support of ultrasound is given The study presented Bayesian belief network containing four phases. The data is preprocessed in the first two phases and

Probabilistic data-driven framework for scoring the preoperative recipient-donor heart transplant survival

68] Health analytics

[69]

Electrophysiology-morphous merging of human heart based on composite visualization approach produces a candidate set of predictors. Medical related variables are added in the third phase and, finally, the model of Bayesian belief network is applied.

The chapter discussed the visualization, analysis, and mining of healthcare data and concludes the way in which data can be proficiently accomplished which further improves the ability of organization to control risk, yield revenue, and cost

The paper presented cardiac electrical excitation propagation model based on the data of human cardia cross-sectional to discover the cardiac electrical activities. After that, biophysical visualization method is applied for the biophysical integration of cardiac anatomy and electrophysiological properties, which provide the equivalent position, spatial relationship, and the whole process in $3 \mathrm{D}$ space with the context of anatomical structure for giving the details of biophysical and electrophysiological activity.

[70] Big data for cardiology: novel discovery?

The paper determined the encouraging data sets for finding of science and the impact on the approaches used in science in general and explicitly in cardiology

The uses of algorithms and intelligent approaches of visualizing

[71] Visualization of medical volume though intelligent approaches medical big data are presented. The article discusses the existing software and toolkits for visualization of medical volume.

Big data are considered to be the main asset of the organization for its successful operations and future endeavour [72-77].

\section{Conclusion}

Healthcare system facilitates the patients with the support of wearable devices, smart devices, handheld devices, and many other devices. These devices are producing a huge bulk of data that need to be moulded for extracting expressive insights from them for the useful use of researchers and practitioners. Various approaches, methods, and tools are in use for doing so and to extract meaningful information in the field of healthcare. This information is being used as evidence to further analyze the data for the early care of patients and to devise treatment. Early care and treatment can facilitate healthcare and patient and can have immense potentiality of quality refining of care and lessen care cost and can decrease waste and chances of error. To facilitate healthcare in general and cardiology in specific, the proposed study presents an overview of the existing literature associated with big data, its insights, and analytics. The presented report will help practitioners and researchers to devise new solutions for early care in healthcare and in cardiology.

\section{Data Availability}

No data were used to support this study.

\section{Conflicts of Interest}

The authors declare no conflicts of interest.

\section{References}

[1] W. Raghupathi and V. Raghupathi, "Big data analytics in healthcare: promise and potential," Health Information Science and Systems, vol. 2, no. 1, 2014.

[2] D. W. Bates, S. Saria, L. Ohno-Machado, A. Shah, and G. Escobar, "Big data in health care: using analytics to identify and manage high-risk and high-cost patients," Health Affairs, vol. 33, no. 7, pp. 1123-1131, 2014

[3] E. A. Mohammed, B. H. Far, and C. Naugler, "Applications of the MapReduce programming framework to clinical big data analysis: current landscape and future trends," BioData Mining, vol. 7, no. 1, 2014.

[4] Y. Wang and N. Hajli, "Exploring the path to big data analytics success in healthcare," Journal of Business Research, vol. 70, pp. 287-299, 2017. 
[5] B. Kayyali, D. Knott, and S. V. Kuiken, "The big-data revolution in us health care: accelerating value and innovation," McKinsey Co., pp. 1-6, 2013.

[6] J. M. Pevnick, K. Birkeland, R. Zimmer, Y. Elad, and I. Kedan, "Wearable technology for cardiology: an update and framework for the future," Trends in Cardiovascular Medicine, vol. 28, no. 2, pp. 144-150, 2018.

[7] N. Mehta, A. Pandit, and S. Shukla, "Transforming healthcare with big data analytics and artificial intelligence: a systematic mapping study," Journal of Biomedical Informatics, vol. 100, p. 103311, 2019.

[8] S. B. Atitallah, M. Driss, W. Boulila, and H. B. Ghézala, "Leveraging Deep Learning and IoT big data analytics to support the smart cities development: review and future directions," Computer Science Review, vol. 38, Article ID 100303, 2020.

[9] J. Kazmierska, "From multisource data to clinical decision aids in radiation oncology: the need for a clinical data science community," Radiotherapy and Oncology, vol. 153, pp. 43-54, 2020.

[10] O. Ben-Assuli, T. Heart, N. Shlomo, and R. Klempfner, "Bringing big data analytics closer to practice: a methodological explanation and demonstration of classification algorithms," Health Policy and Technology, vol. 8, no. 1, pp. 7-13, 2019.

[11] D. Itchhaporia, "Artificial intelligence in cardiology," Trends in Cardiovascular Medicine, 2020, In press.

[12] S. Nazir, M. Nawaz, A. Adnan, S. Shahzad, and S. Asadi, "Big data features, applications, and analytics in cardiology-A systematic literature review," IEEE Access, vol. 7, pp. 143742-143771, 2019.

[13] S. Nazir, M. Nawaz Khan, S. Anwar et al., "Big data visualization in cardiology-A systematic review and future directions," IEEE Access, vol. 7, pp. 115945-115958, 2019.

[14] P. Bizopoulos and D. Koutsouris, "Deep learning in cardiology," IEEE Reviews in Biomedical Engineering, vol. 12, pp. 168-193, 2019.

[15] H. D. Cannière, "The progression of heart rate variability parameters throughout cardiac rehabilitation," Computing in Cardiology, vol. 8-11, pp. 1-4, 2019.

[16] R. W. Treskes, E. T. Van der Velde, J. W. Schoones, and M. J. Schalij, "Implementation of smart technology to improve medication adherence in patients with cardiovascular disease: is it effective?" Expert Review of Medical Devices, vol. 15, no. 2, pp. 119-126, 2018.

[17] A. Naseer, B. Y. Alkazemi, and E. U. Waraich, "A big data approach for proactive healthcare monitoring of chronic patients," in Proceedings of the 2016 Eighth International Conference on Ubiquitous and Future Networks (ICUFN), Vienna, Austria, July 2016.

[18] G. Luo, G. Sun, K. Wang, S. Dong, and H. Zhang, "A novel left ventricular volumes prediction method based on deep learning network in cardiac MRI," in Proceedings of the 2016 Computing in Cardiology Conference (CinC), Vancouver, Canada, 2016.

[19] C. B. Rjeily, G. Badr, A. H. E. Hassani, and E. Andres, "Medical data mining for heart diseases and the future of sequential mining in medical field (machine learning paradigms)," Machine Learning Paradigms,Intelligent Systems Reference Library, vol. 149, pp. 71-99, 2018.

[20] L. E. Juarez-Orozco, O. Martinez-Manzanera, S. V. Nesterov, S. Kajander, and a. J. Knuuti, "The machine learning horizon in cardiac hybrid imaging," European Journal of Hybrid Imaging, vol. 2, no. 15, pp. 1-15, 2018.
[21] M. F. B. Mustapha and D. T. Anw, "Mobile heart rate monitor for myocardial infarction patients," in Proceedings of the 2017 6th ICT International Student Project Conference (ICT-ISPC), Skudai, Malaysia, May 2017.

[22] H. Elsadig, M. Weiss, J. Scott, and R. Laaksonen, "Use of clinical guidelines in cardiology practice inSudan," Journal of Evaluation in Clinical Practice, vol. 24, no. 1, pp. 127-134, 2018.

[23] D. Seth, N. Biswas, and D. Ghosh, "Big health data: cardiac remodelling and functional interactions of big brain based implications in body sensor networks," in Proceedings of the 2017 7th International Conference on Communication Systems and Network Technologies, Nagpur, India, November 2017.

[24] H. Hemingway, F. W. Asselbergs, J. Danesh et al., "Big data from electronic health records for early and late translational cardiovascular research: challenges and potential," European Heart Journal, vol. 39, no. 16, pp. 1481-1495, 2018.

[25] Y. Luo, F. S. Ahmad, and S. J. Shah, “Tensor factorization for precision medicine in heart failure with preserved ejection fraction," Journal of Cardiovascular Translational Research, vol. 10, no. 3, pp. 305-312, 2017.

[26] Y. H. Tang, M. C. Chong, Y. P. Chua, P. L. Chui, L. Y. Tang, and N. Rahmat, "The effect of mobile messaging apps on cardiac patient knowledge of coronary artery disease risk factors and adherence to a healthy lifestyle," Journal of Clinical Nursing, vol. 27, pp. 4311-4320, 2018.

[27] S.-W. Liou, D. Kurniadi, B.-R. Zheng, W.-Q. Xie, C.-J. Tien, and G.-J. Jong, "Classification of biomedical signal on IoT platform using support vector machine," in Proceedings of IEEE International Conference on Applied System Innovation, Chiba, Japan, April 2018.

[28] Z. Taimeh, D. Duprez, and D. J. Garry, "Heart failure prevention," Proceedings of the Congestive Heart Failure and Cardiac Transplantation, vol. 6, no. 8, pp. 1120-1128, 2017.

[29] C. Piazzese, M. ChiaraCarminati, and E. G. Caiani, "Statistical shape models of the heart: applications to cardiac imaging," in Statistical Shape and Deformation Analysis Methods, pp. 445-480, Elseiver, Amsterdam, Netherlands, 2017.

[30] R. G. Saboji and P. K. Ramesh, "A scalable solution for heart disease prediction using classification mining technique," in Proceedings of the International Conference on Energy, Communication, Data Analytics and Soft Computing (ICECDS-2017), Chennai, India, August 2017.

[31] A. Mustaqeem, S. M. Anwar, A. R. Khan, and M. Majid, “A statistical analysis based recommender model for heart disease patients," International Journal of Medical Informatics, vol. 108, pp. 134-145, 2017.

[32] K. Gilbert, B. Pontre, C. J. Occleshaw, B. R. Cowan, A. Suinesiaputra, and A. A. Young, "4D modelling for rapid assessment of biventricular function in congenital heart disease," The International Journal of Cardiovascular Imaging, vol. 34, no. 3, pp. 407-417, 2018.

[33] K. T. Lee, A. L. Hour, B. C. Shia, and P. H. Chu, "The application and future of big database studies in cardiology: a single-center experience," Acta Cardiologica Sinica, vol. 33, no. 6, pp. 581-587, 2017.

[34] C. A. Ledezma, "A big data approach to myocyte membrane analysis: using populations of models to understand the cellular causes of heart failure," in Proceedings of the Computing in Cardiology, Vancouver, Canada, September 2017.

[35] L. X. Lu and S. F. Lu, "Distance, quality, or relationship? Interhospital transfer of heart attack patients," Production and Operations Management, vol. 27, no. 12, pp. 2251-2269, 2017. 
[36] R. El-Bialy, M. A. Salamay, O. H. Karam, and M. E. Khalifa, "Feature analysis of coronary artery heart disease data sets," in Proceedings of the International Conference on Communication, Management and Information Technology (ICCMIT 2015), Prague, Czech Republic, April 2015.

[37] H. Mizuno, "Mapping of ventricular tachycardia in patients with structural heart disease," Journal of Arrhythmia, vol. 30, no. 4, pp. 283-291, 2014.

[38] S. Abohammar, M. A. ElSaidy, D. Fathalla, and M. Aldosarri, "Baseline characteristics of patients with heart failure and preserved ejection fraction at admission with acute heart failure in Saudi Arabia," The Egyptian Heart Journal, vol. 69, no. 1, pp. 21-28, 2017.

[39] A. Idri and I. Kadi, "A data mining-based approach for cardiovascular dysautonomias diagnosis and treatment," in Proceedings of the 2017 IEEE International Conference on Computer and Information Technology, Helsinki, Finland, August 2017.

[40] A. B. Christian, L. Sharma, and S.-L. Wu, "AED: adaptive energy-efficient data transmission scheme for heart disease detection," in Proceedings of the 2017 IEEE 15th International Conference on Dependable, Autonomic and Secure Computing, 15th International Conference on Pervasive Intelligence and Computing, 3rd International Conference on Big Data Intelligence and Computing and Cyber Science and Technology Congress, Orlando, FL, USA, November 2017.

[41] C. A. Alexander and a. L. Wang, "Big data analytics in heart attack prediction," Journal of Nursing and Care, vol. 6, no. 2, pp. 1-9, 2017.

[42] Q. Wang, W. Xiong, Y. Zhang et al., "Remote analysis of myocardial fiber information in vivo assisted by cloud computing," Future Generation Computer Systems, vol. 85, pp. 146-159, 2018.

[43] C. A. Ledezma, "Evaluating the risks of arrhythmia through big data: automatic processing and neural networks to classify epicardial electrograms," in Proceedings of the Computing in Cardiology 2017, Rennes, France, September 2017.

[44] A. M. S. Omar, "Imaging based big data and machine learning framework for rapid phenotyping OF left ventricular diastolic function," Journal of the American College of Cardiology, vol. 67, no. 13, p. 1614, 2016.

[45] Y. Shi, "Automatic knowledge extraction and data mining from echo reports of pediatric heart disease: application on clinical decision support," in Proceedings of the Chinese Computational Linguistics and Natural Language Processing Based on Naturally Annotated Big Data, Changsha, China, October 2015.

[46] A. Dag, K. Topuz, A. Oztekin, S. Bulur, and F. M. Megahed, “A probabilistic data-driven framework for scoring the preoperative recipient-donor heart transplant survival," Decision Support Systems, vol. 86, pp. 1-12, 2016.

[47] O. Behadada, M. Trovati, M. Chikh, and N. Bessis, "Big databased extraction of fuzzy partition rules for heart arrhythmia detection: a semi-automated approach," Concurrency and Computation: Practice and Experience, vol. 28, no. 2, pp. 360-373, 2016.

[48] G. Vaishali and V. Kalaivani, "Big data analysis for heart disease detection system using map reduce technique," in Proceedings of the 2016 International Conference on Computing Technologies and Intelligent Data Engineering (ICCTIDE'16), Kovilpatti, India, January 2016.

[49] C. M. Bucci, W. E. Legnani, and R. L. Armentano, "Clustering of cardiovascular risk factors highlighted the coronary artery calcium as a strong clinical discriminator," Health and Technology, vol. 6, no. 3, pp. 159-165, 2016.

[50] B. Urrea, "Mobile health initiatives to improve outcomes in primary prevention of cardiovascular disease," Current Treatment Options in Cardiovascular Medicine, vol. 17, no. 12, pp. 1-12, 2015.

[51] A. P. Hill, M. D. Perry, N. Abi-Gerges et al., "Computational cardiology and risk stratification for sudden cardiac death: one of the grand challenges for cardiology in the 21st century," The Journal of Physiology, vol. 594, no. 23, pp. 6893-6908, 2016.

[52] H. H. Nguyen and J. N. A. A. Silva, "Use of smartphone technology in cardiology," Trends in Cardiovascular Medicine, vol. 26, no. 4, pp. 376-386, 2016.

[53] S. Walton, K. Berger, J. Thiyagalingam et al., "Visualizing cardiovascular magnetic resonance (CMR) imagery: challenges and opportunities," Progress in Biophysics and Molecular Biology, vol. 115, no. 2-3, pp. 349-358, 2014.

[54] R. U. Shah and J. S. Rumsfeld, "Big data in cardiology," European Heart Journal, vol. 38, no. 24, pp. 1865-1867, 2017.

[55] J. Kim, "Big data, health informatics, and the future of cardiovascular medicine," Journal of the American College of Cardiology, vol. 69, no. 7, pp. 899-902, 2017.

[56] J. Lee, E. Ribey, and J. R. Wallace, "A web-based data visualization tool for the MIMIC-II database," BMC Medical Informatics and Decision Making, vol. 16, no. 15, pp. 1-8, 2016.

[57] E. Lau, K. E. Watson, and P. Ping, "Connecting the dots," Circulation, vol. 134, no. 5, pp. 362-364, 2016.

[58] G. Kopanitsa, A. Karpov, G. Lakovenko, and A. Laskovenko, "Implementation of a web portal for diabetes patients using open source data visualization libraries," Studies in Health Technology and Informatics, vol. 224, pp. 189-194, 2016.

[59] M. Ciecholewski, "Ischemic heart disease detection using selected machine learning methods," International Journal of Computer Mathematics, vol. 90, no. 8, pp. 1734-1759, 2013.

[60] A. Asante-Korang and J. P. Jacobs, "Big Data and paediatric cardiovascular disease in the era of transparency in healthcare," Cardiology in the Young, vol. 26, no. 8, pp. 1597-1602, 2016.

[61] M. Zastrow, "Data visualization: science on the map, Easy-touse mapping tools give researchers the power to create beautiful visualizations of geographic data," Nature International Weekly Journal of Science, vol. 519, no. 7541, pp. 1-2, 2015.

[62] S. B. Scruggs, "Harnessing the heart of big data," Circulation Research, pp. 1-11, 2015.

[63] M. W. Jenkins and A. M. Rollins, "4-D OCT in developmental cardiology," Optical Coherence Tomography, vol. 116, pp. 2003-2023, 2015.

[64] A. H. Basori, M. R. B. D. A. Kadir, R. M. Ali, F. Mohamed, and S. Kadiman, "Kinect-based gesture recognition in volumetric visualisation of heart from cardiac magnetic resonance (CMR) imaging," Virtual, Augmented Reality and Serious Games for Healthcare 1, Intelligent Systems Reference Library, vol. 68, pp. 79-92, 2014.

[65] T. J. Brigham, "Feast for the eyes: an introduction to data visualization," Medical Reference Services Quarterly, vol. 35, no. 2, pp. 215-223, 2016.

[66] J. D'hooge, "Cardiac 4D ultrasound imaging," in Biomedical Image Processing, Biological and Medical Physics, Biomedical Engineering, pp. 81-104, Springer, Berlin, Germany, 2011.

[67] A. Dag, K. Topuz, A. Oztekin, S. Bulur, and F. M. Megahed, "A probabilistic data-driven framework for scoring the 
preoperative recipient-donor heart transplant survival," $D e$ cision Support Systems, vol. 86, pp. 1-12, 2018.

[68] P. M. Griffin, H. B. Nembhard, C. J. DeFlitch, N. D. Bastian, H. Kang, and D. A. Muñoz, "Health analytics," in Healthcare Systems EngineeringEuropian society of cardiology, Sophia Antipolis, France, 2016.

[69] F. Yang, "A composite visualization method for electrophysiology-morphous merging of human heart," BioMed Eng OnLine, vol. 16, no. 70, pp. 1-16, 2017.

[70] V. Mayer-Schönberger, "Big Data for cardiology: novel discovery?" European Heart Journal, vol. 37, no. 12, pp. 996-1001, 2016.

[71] Y. Abdallah, A. Abdelhamid, T. Elarif, and A.-B. M. Salem, "Intelligent techniques in medical volume visualization," Procedia Computer Science, vol. 65, pp. 546-555, 2015.

[72] S. Nazir, S. Khan, H. U. K. S. Ali, I. García-Magariño, R. B. Atan, and M. Nawaz, "A comprehensive analysis of healthcare big data management, analytics and scientific programming," IEEE Access, vol. 8, 2020.

[73] A. U. Haq, "Intelligent machine learning approach for effective recognition of diabetes in the e-healthcare using clinical data," Sensors, vol. 20, no. 9, p. 2649, 2020.

[74] S. Khan, S. Nazir, I. García-Magariño, and A. Hussain, “Deep learning based urban big data fusion in smart cities: towards traffic monitoring and flow-preserving fusion," Computers \& Electrical Engineering, vol. 89, Article ID 106906, 2020.

[75] X. Liao, S. Nazir, Y. zhou, M. Shafiq, and X. Qi, "User knowledge, data modelling and visualization- handling through fuzzy logic based approach," Journal of Structural Geology, vol. 141, 2020.

[76] S. Nazir, S. Ali, M. Yang, and Q. Xu, "Deep learning algorithms and multi-criteria decision making used in big data- a systematic literature review," Complexity, vol. 2020, Article ID 2836064, 18 pages, 2020.

[77] J. Chi, Y. Li, J. Huang et al., "A secure and efficient data sharing scheme based on blockchain in industrial Internet of things," Journal of Network and Computer Applications, vol. 167, p. $102710,2020$. 